\title{
Pharmacokinetics and Antiinflammatory Effect of a Novel Gel System Containing Ketoprofen Solid Nanoparticles
}

\author{
Noriaki Nagai,* Aya Iwamae, Shion Tanimoto, Chiaki Yoshioka, and Yoshimasa Ito \\ School of Pharmacy, Kinki University; 3-4-1 Higashi-Osaka, Osaka 577-8502, Japan. \\ Received July 16, 2015; accepted September 16, 2015
}

We previously reported that dermal application using nanoparticles improves skin penetration. In this study, we prepared novel topical formulations containing ketoprofen (KET) solid nanoparticles (KET ${ }_{\text {nano }}$ gel ointment) and investigated the antiinflammatory effect of the KET nanoparticle formulations on rheumatoid arthritis using adjuvant-induced arthritis (AA) rats. The KET $_{\text {nano }}$ gel ointment was prepared using a bead mill method and additives including methylcellulose and Carbopol 934; the mean particle size of the KET nanoparticles was $83 \mathrm{~nm}$. In the in vitro skin penetration experiment, the penetration rate $\left(J_{c}\right)$ and penetration coefficient through the skin $\left(K_{\mathrm{p}}\right)$ values of the $\mathrm{KET}_{\text {nano }}$ gel ointment were significantly higher than those of gel ointment containing KET microparticles $\left(\mathrm{KET}_{\text {micro }}\right.$ gel ointment; mean particle size $\left.7.7 \mu \mathrm{m}\right)$. On the other hand, in the in vivo percutaneous absorption experiment, the apparent absorption rate constant $\left(k_{\mathrm{a}}\right)$ and the areas under the KET concentration-time curve values in the skin of rats receiving the KET $_{\text {nano }}$ gel ointment were significantly higher than those of rats receiving the $\mathrm{KET}_{\text {micro }}$ gel ointment, and the amounts of KET in the skin tissues of rats receiving the $\mathrm{KET}_{\text {nano }}$ gel ointment were also significantly higher than those of rats receiving the $\mathrm{KET}_{\text {micro }}$ gel ointment. In addition, the application of the $\mathrm{KET}_{\text {nano }}$ gel ointment attenuated the enhancement of paw edema of the hind feet of AA rats more than the application of the KET micro $_{\text {gel oint- }}$ ment. Our findings suggest that a topical drug delivery system using nanoparticles could lead to expansion in the therapeutic use of KET.

Key words nanoparticle; ketoprofen; gel ointment; drug delivery; adjuvant-induced arthritis

Ketoprofen (KET) is a reversible inhibitor of cyclooxygenases 1 and 2 whose action leads to a reduction in the formation of prostaglandin precursors. ${ }^{1)}$ Thus, KET acts as an antiinflammatory agent, and is used in the treatment of rheumatoid arthritis (RA) and osteoarthritis. However, its usefulness is limited due to its low water solubility and the fact that oral administration of KET tends to cause gastrointestinal lesions in $10-30 \%$ of patients. These gastrointestinal lesions lead to an interruption of drug therapy in about $5-15 \%$ patients. ${ }^{2,3}$ Topical and transdermal delivery routes of drug administration reduce the incidence of gastrointestinal lesions and improve patient compliance. Furthermore, the transdermal route of application avoids hepatic first pass metabolism, meaning that therapeutic serum drug concentrations can be applied with a reduced risk of nephrotoxicity and drug-drug interactions. ${ }^{2)}$ However, the transdermal route of application is limited by the barrier properties of the skin. Therefore, it is necessary to develop enhancement techniques to assist the skin penetration of KET, and extensive research has been done to find both topical and transdermal KET formulations. ${ }^{1,4-6)}$

To improve the delivery of KET through the skin, several techniques have been employed as follows: liposomes, ${ }^{7)}$ gels, ${ }^{8,9)}$ ointments, creams, ${ }^{10)}$ patches ${ }^{11,12)}$ incorporating various permeation enhancers, micro-needle treatment, ${ }^{13)}$ iontophoresis ${ }^{14,15)}$ and therapeutic frequency sonophoresis (1 MHz) ${ }^{16,17)}$ Recently, strategies using nanoparticles have been developed and investigated as nanomedicines. ${ }^{18-26)}$ The particle size influences their functionality in terms of uptake, residence time in circulation, adherence, and degradation. ${ }^{27-31)}$ Also, we have reported that dermal applications employing nanoparticles enhance skin penetration of the drug. ${ }^{32,33)}$ It is expected that nanoparticles may provide an alternative strategy for improving drug skin permeation, ${ }^{34-37)}$ and it is possible that the therapeutic use of KET may be expanded by the development of a topical drug delivery system using nanoparticles.

Here, we have designed novel topical formulations containing KET solid nanoparticles, and investigated the anti-inflammatory effect of these KET nanoparticle formulations on RA by using adjuvant-induced arthritis (AA) rats. In addition, we demonstrate the enhancement mechanism of skin penetration in drug nanoparticle formulations by comparing the present data with previous reports [skin penetration parameters for gel ointments containing solid tranilast (TL) or indomethacin (IMC) nanoparticles]. ${ }^{32,33)}$

\section{MATERIALS AND METHODS}

Animals Male 7-week-old Wistar rats, and 6-13-week-old Dark Agouti (DA) rats were used in this study. All animal experiments were carried out in accordance with the Kinki University School of Pharmacy Committee for the Care and Use of Laboratory Animals.

Chemicals Low-substituted methylcellulose (MC, METOLOSE SM-4, average viscosity, $4 \mathrm{~Pa} \cdot \mathrm{s}$ at $20^{\circ} \mathrm{C}$ ) was provided by Shin-Etsu Chemical Co., Ltd. (Tokyo, Japan). Carboxypolymethylene $\left(\right.$ Carbopol $^{\circledR}$ 934) was obtained from Serva (Heidelberg, Germany). Conventional KET (solid, KET microparticles, $7.7 \pm 0.28 \mu \mathrm{m}$, the mean \pm standard deviation (S.D.)) and commercially available KET gel (SECTOR gel ${ }^{\circledR}$ 3\%) were purchased from Wako Pure Chemical Industries, Ltd. (Osaka, Japan) and Hisamitsu Pharmaceutical Co., Inc. (Tokyo, Japan), respectively. All other chemicals used were of the highest purity commercially available.

Preparation of Gel Ointment Containing KET Nanopar- 
ticles The gel ointment containing drug nanoparticles (nano gel ointment) was prepared according to our previous reports. ${ }^{32,33)}$ Conventional KET with MC was crushed with the Bead Smash 12 (a bead mill, Wakanyaku Co., Ltd., Kyoto, Japan), ${ }^{32,33,38-41)}$ to yield milled KET with a particle size of $0.071 \pm 0.046 \mu \mathrm{m}$ (the mean \pm S.D.). After milling, the KET nanoparticles were added to the Carbopol $^{\circledR} 934$ gel base (KET ${ }_{\text {nano }}$ gel ointment). The Carbopol ${ }^{\circledR} 934$ gel base was made as follows: Carbopol $^{\circledR} 934$ (Serva, Heidelberg, Germany) was added to distilled water, allowed to swell for $1 \mathrm{~h}$ at room temperature, and neutralized with 5\% ammonia water (gel base). The gel ointment containing drug microparticles (micro gel ointment) was prepared by mixing KET microparticles and $\mathrm{MC}$ in $\mathrm{Carbopol}^{\circledR} 934$ gel base $\left(\mathrm{KET}_{\text {micro }}\right.$ gel ointment). The formulation of the KET gel ointments is as follows: $3 \%$ KET, 0.5\% MC, 3\% Carbopol ${ }^{\circledR}$ 934, w/w\%. The dispersity of the nanoparticles in the ointment base was confirmed as follows: KET gel ointments were divided into 10 parts, and kept at $22^{\circ} \mathrm{C}$ in the dark for 1 month. The KET particle size in each part was determined by a nanoparticle size analyzer SALD-7100 (Shimadzu Corp., Kyoto, Japan; refractive index 1.70-0.010i). The KET concentration was measured using a Shimadzu LC-20AT system equipped with a column oven CTO-20 A (Shimadzu Corp.) and an Inertsil ${ }^{\circledR}$ ODS-3 $(3 \mu \mathrm{m}$, column size: $2.1 \mathrm{~mm} \times 50 \mathrm{~mm}$ ) column (GL Science Co., Inc., Tokyo, Japan). The mobile phase consisted of methanol- $0.05 \%$ trifluoroacetic acid $(50: 50, \mathrm{v} / \mathrm{v})$ at a flow rate of $0.25 \mathrm{~mL} / \mathrm{min}$. The column temperature was $35^{\circ} \mathrm{C}$, the wavelength for detection was $260 \mathrm{~nm}$, and $1 \mu \mathrm{g} / \mathrm{mL}$ propyl $p$-hydroxybenzoate was used as an internal standard.

Release of KET from KET Gel Ointments Using a Franz Diffusion Cell The conditions of the drug release experiment from the gel ointments were the same as described in our previous reports. ${ }^{32,33)}$ Membrane filters with pore sizes of 25 and $220 \mathrm{~nm}\left(\mathrm{MF}^{\mathrm{TM}}\right.$-MEMBRANE FILTER, Merck Millipore, Tokyo, Japan) and a Franz diffusion cell were used in this study. $0.3 \mathrm{~g}$ KET gel ointment was spread uniformly over the membrane, which was then mounted in the Franz diffusion cell with $1.6 \mathrm{~cm}$ i.d. $O$-ring flange. The diffusion cells were thermoregulated in a water bath at $37^{\circ} \mathrm{C}$ for $24 \mathrm{~h}$. One hundred microliter aliquots of sample solution were withdrawn from the reservoir chamber (reservoir volume $12.2 \mathrm{~mL}$ ), and the KET concentrations in the samples were determined by the HPLC method described above.

In Vitro Skin Penetration of KET Gel Ointments The collection of abdominal skin was performed according to our previous reports, ${ }^{32,33)}$ and the conditions of the experiment were the same as the method using the Franz diffusion cell described above. The data obtained were analyzed according to the following equations ${ }^{32,33)}$ (Eqs. 1-3):

$$
\begin{gathered}
t_{\mathrm{lag}}=\frac{\delta^{2}}{6 D} \\
J_{\mathrm{c}}=\frac{K_{\mathrm{m}} \cdot D \cdot C_{\mathrm{KET}}}{\delta}=K_{\mathrm{p}} \cdot C_{\mathrm{KET}} \\
Q_{\mathrm{t}}=J_{\mathrm{c}} \cdot A \cdot\left(T-t_{\mathrm{lag}}\right)
\end{gathered}
$$

where $J_{\mathrm{c}}, K_{\mathrm{m}}, K_{\mathrm{p}}, D, t_{\text {lag }}, \delta, Q_{\mathrm{t}}$, and $A$ are the KET penetration rate, skin/preparation partition coefficient, penetration coefficient through the skin, diffusion constant within the skin, lag time, thickness of the skin $(0.071 \mathrm{~cm}$, mean of 5 independent rats), total amount of KET appearing in the reservoir solution at time $t$, and effective area of skin $\left(2 \mathrm{~cm}^{2}\right)$. A nonlinear leastsquares computer program (MULTI) was employed for the calculations. ${ }^{32,33,42)}$

In Vivo Percutaneous Absorption of KET Gel Ointments The topical application of $0.3 \mathrm{~g}$ KET gel ointment and collection of blood were performed according to our previous reports. ${ }^{32,33)}$ The blood was centrifuged $\left(800 \times \boldsymbol{g}, 20 \mathrm{~min}, 4^{\circ} \mathrm{C}\right)$, and the KET concentrations in the samples (plasma) were determined by the HPLC method described above. The KET concentration in the plasma after a single injection $(650 \mu \mathrm{g} /$ $\mathrm{kg}, 0.3 \mathrm{~mL}$ ) of KET solution containing $1 \%$ dimethyl sulfoxide into the femoral vein was calculated according to Eq. $4^{43)}$ :

$$
C_{\mathrm{KET}}=A \cdot \mathrm{e}^{-\alpha \cdot t}+B \cdot \mathrm{e}^{-\beta \cdot t}
$$

where $t, \quad C_{\mathrm{KET}}, \quad A \quad(10.9 \pm 1.87 \mathrm{nmol} / \mathrm{mL}, \quad n=6) \quad$ and $B$ $(6.14 \pm 0.47 \mathrm{nmol} / \mathrm{mL}, n=6)$ are time $(0-120 \mathrm{~min})$ after KET injection, concentration of KET at the corresponding time, and KET concentrations in the $\alpha$ - and $\beta$-phases, respectively. $\alpha$ $\left(33.0 \pm 5.6 \mathrm{~h}^{-1}\right)$ and $\beta\left(0.47 \pm 0.11 \mathrm{~h}^{-1}\right)$ show the elimination rate constants in the first and second phases (the mean \pm standard error (S.E.), $n=6$ ).

The percutaneous absorption of KET gel ointment was analyzed according to Eq. $5^{43)}$ :

$$
\begin{aligned}
C_{\mathrm{KET}}= & \frac{A \cdot k_{\mathrm{a}}}{k_{\mathrm{a}}-\alpha} \mathrm{e}^{-\alpha\left(t-t_{\mathrm{ag}}\right)}+\frac{B \cdot k_{\mathrm{a}}}{k_{\mathrm{a}}-\beta} \mathrm{e}^{-\beta\left(t-t_{\mathrm{ag}}\right)} \\
& -\left(\frac{A \cdot k_{\mathrm{a}}}{k_{\mathrm{a}}-\alpha}+\frac{B \cdot k_{\mathrm{a}}}{k_{\mathrm{a}}-\beta}\right) \mathrm{e}^{-k_{\mathrm{a}}\left(t-t_{\mathrm{lag}}\right)}
\end{aligned}
$$

where $C_{\mathrm{KET}}, k_{\mathrm{a}}, t, t_{\text {lag }}$, are the KET concentration in the plasma, absorption rate constant $\left(\mathrm{h}^{-1}\right)$, time $(0-24 \mathrm{~h})$ after KET administration, and lag time (h), respectively. MULTI was used in these these calculations (Eqs. 4 and 5).

The area under the KET concentration-time curve $(A U C)$, area under the first moment curve $(A U M C)$ and mean residence time $(M R T)$ were calculated according to the following equations (Eqs. 6-8):

$$
\begin{gathered}
A U C=\int_{0 \mathrm{~h}}^{24 \mathrm{~h}} C_{\mathrm{KET}} \mathrm{d} t+\frac{C_{\mathrm{KET} \text { at } 24 \mathrm{~h}}}{\beta} \\
A U M C=\int_{0 \mathrm{~h}}^{\infty \mathrm{h}} C_{\mathrm{KET}} \cdot t \mathrm{~d} t \\
M R T=\frac{A U M C}{A U C}
\end{gathered}
$$

Accumulation of KET Gel Ointment in Skin Tissue The accumulation of KET gel ointment in the skin tissue was measured according to our previous reports. ${ }^{32,33)}$ The hair on the abdominal area was removed on the day before the experiment, and $0.3 \mathrm{~g}$ of KET gel ointment was fixed on the shaved abdominal skin. When collecting the skin tissue, the gel ointment on the skin surface was wiped off, and the abdominal skin to which the KET gel ointments were applied was excised. The skin samples obtained were homogenized in methanol, and the homogenates were centrifuged $(20400 \times \boldsymbol{g}$, $20 \mathrm{~min}, 4^{\circ} \mathrm{C}$ ). The KET concentrations in the supernatants were determined by the HPLC method described above. 
Application of KET Gel Ointments to RA Model Rats The experiment was performed according to our previous reports. ${ }^{32,33)}$ Adjuvant [Bayol $\mathrm{F}$ oil containing $10 \mathrm{mg} / \mathrm{mL}$ heatkilled Mycobacterium butyricum (Difco, Detroit, MI, U.S.A.)] was injected into the right hind foot and tail of DA rats. The control group received $50 \mu \mathrm{L}$ of Bayol $\mathrm{F}$ oil. The application of KET gel ointments was started after adjuvant injection, and $0.3 \mathrm{~g}$ of KET gel ointment was applied to the right foot daily (9:00). When reapplying the gel ointment, the old gel ointment on the skin surface was first wiped off with saline. The inflammation of AA was quantified by the differences in paw volume of the arthritis and normal rats.

The inflammatory scores are represented as $A U C_{\text {edema }}$ (the area under the paw volume-time curve) following equation (Eq. 9):

$$
A U C_{\text {edema }}=\int_{0 \mathrm{~d}}^{42 \mathrm{~d}} V_{\text {edema }} \mathrm{d} t
$$

where $V$ and $t$ are the volume of paw edema and the days after adjuvant injection, respectively.

Statistical Analysis $p$ Values less than 0.05 were considered significant in this study. Unpaired Student's or AspinWelch's $t$-tests were used to determine statistical difference, and multiple groups were evaluated by one-way ANOVA followed by Dunnett's multiple comparison.

\section{RESULTS AND DISCUSSION}

Evaluation of the Stability of KET in Gel Ointments Containing KET Solid Nanoparticles In a previous study, we found that the addition of MC permits the preparation of nanoparticles by mill methods. ${ }^{32,33,38-40)}$ According to these reports, the KET nanoparticles were prepared using MC and Bead Smash 12. Although the bead mill method using KET microparticles produced a meringue state, the addition of
$\mathrm{MC}$ resulted in the preparation of KET nanoparticles. The prepared KET nanoparticles were of high quality, since the particle size of the milled-KET was less than $100 \mathrm{~nm}$, and the nanoparticles were homogeneous with a narrow particle size distribution (particle size $71 \pm 46 \mathrm{~nm}$, mean \pm S.D.). We also reported that Carbopol 934 allows the uniform incorporation and release of the nanoparticles, and these finding showed that Carbopol 934 is suitable for the preparation of dermal formulations containing nanoparticles. ${ }^{32,33)}$ Therefore, Carbopol 934 was used to prepare a gel ointment containing KET solid nanoparticles. The mean particle size in the $3 \% \mathrm{KET}_{\text {micro }}$ and $\mathrm{KET}_{\text {nano }}$ gel ointments was $7.7 \pm 0.30 \mu \mathrm{m}$, and $0.083 \pm 0.071 \mu \mathrm{m}$ (mean \pm S.D., Fig. 1), respectively. Carbopol 934 has excellent thickening, emulsifying and gelling properties that allow the uniform incorporation of the KET nanoparticles. The KET ${ }_{\text {micro }}$ and $\mathrm{KET}_{\text {nano }}$ gel ointments were stable for one month after preparation (mean particle size: $\mathrm{KET}_{\text {micro }}, 7.8 \pm 0.39 ; \mathrm{KET}_{\text {nano, }}$ 0.091 $\pm 0.083, \mu \mathrm{m}$, mean \pm S.D.), with no decrease in KET concentration in either ointment observed during one month stored at $22^{\circ} \mathrm{C}$.

Percutaneous Penetration of KET Released from KET micro $_{\text {. }}$ and KET $_{\text {nano }}$ Gel Ointments The drug release from and skin penetration of $\mathrm{KET}_{\text {nano }}$ gel ointments were evaluated. Although KET release from the $\mathrm{KET}_{\text {nano }}$ gel ointment through the 25 and $220 \mathrm{~nm}$ pore size membranes was significantly higher than that from the $\mathrm{KET}_{\text {micro }}$ gel ointment, the KET penetration profile of the $\mathrm{KET}_{\text {nano }}$ gel ointment through the $25 \mathrm{~nm}$ pore size membrane was significantly lower than that through the $220 \mathrm{~nm}$ pore size membrane (Fig. 2). On the other hand, $\mathrm{KET}$ release from the $\mathrm{KET}_{\text {micro }}$ gel ointment was similar in experiments using 25 and $220 \mathrm{~nm}$ pore size membranes (Fig. 2). This result suggests that the KET released from $K_{E T}$ nano gel ointment remains in the nanoparticle state. Figure 3 shows the penetration profiles of KET through rat skin following the application of $\mathrm{KET}_{\text {micro }}$ or $\mathrm{KET}_{\text {nano }}$ gel ointments. The amounts
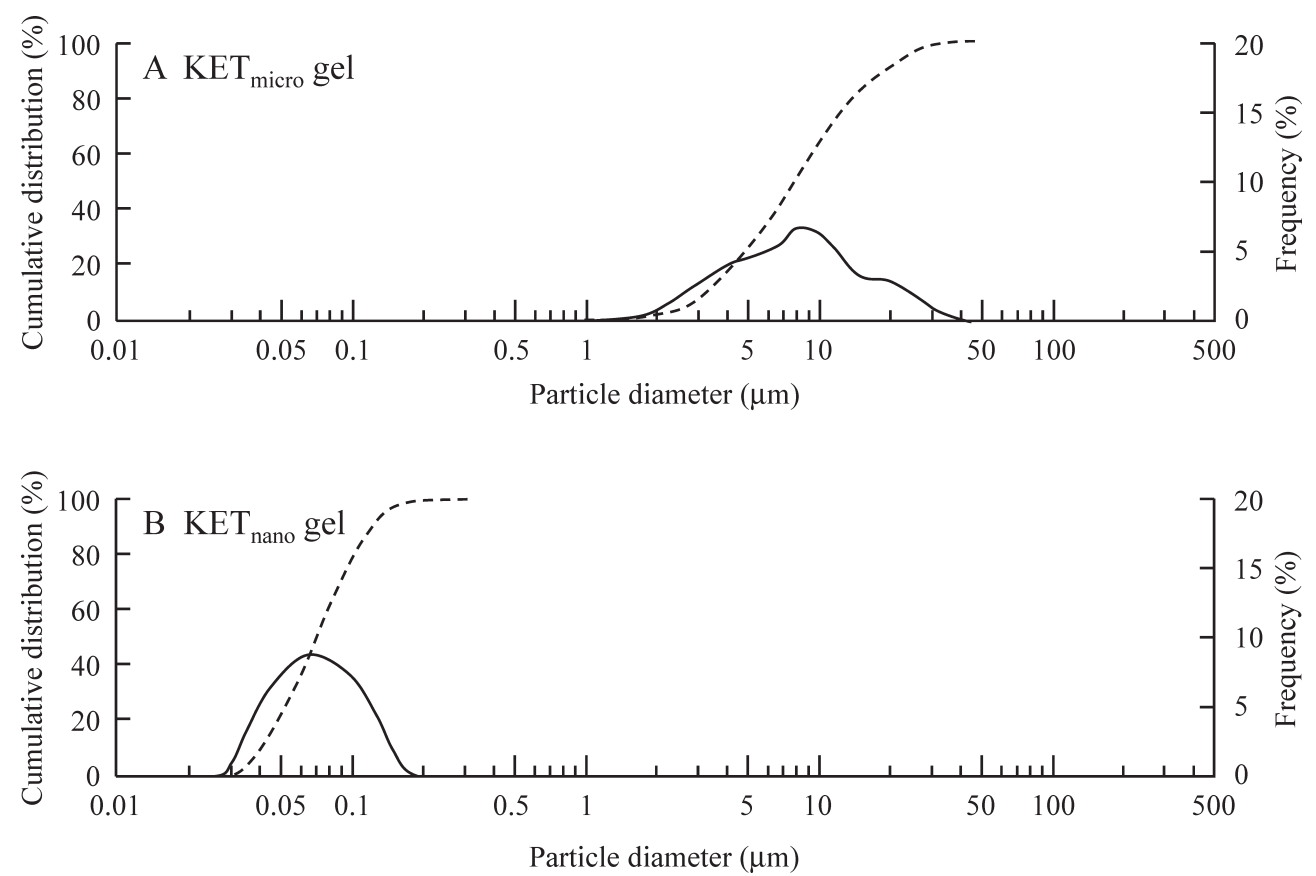

Fig. 1. Cumulative Particle Size Distribution and Frequency in $3 \% \mathrm{KET}_{\text {micro }}$ (A) and $\mathrm{KET}_{\text {nano }}$ (B) Gel Ointments

Dashed line, cumulative size distribution; solid line, cumulative size frequency. Mean particle size: $\mathrm{KET}_{\text {micro }}$ gel ointment, $7.7 \pm 0.30 \mu \mathrm{m}$; KET $\mathrm{nano}_{\text {gel }}$ ointment, $0.083 \pm 0.071 \mu \mathrm{m} ;$ mean \pm S.D. 
of penetrated KET increased linearly after the application of either KET gel ointment, but the $J_{\mathrm{c}}$ and $K_{\mathrm{p}}$ values of the $\mathrm{KET}_{\text {nano }}$ gel ointment were significantly higher than those of the $\mathrm{KET}_{\text {micro }}$ gel ointment (Table 1). The $K_{\mathrm{m}}, D$ and $t_{\text {lag }}$ for the $\mathrm{KET}_{\text {micro }}$ and $\mathrm{KET}_{\text {nano }}$ gel ointments showed no significant differences (Table 1). On the other hand, in the in vivo percutaneous absorption experiments using rats, the $k_{\mathrm{a}}$ and $A U C$ values in the skin of rats receiving the $\mathrm{KET}_{\text {nano }}$ gel ointment were significantly higher than those of rats receiving the $\mathrm{KET}_{\text {micro }}$ gel ointment (Fig. 4, Table 2). The reduction of $t_{\text {lag }}$ and extension of $M R T$ for the $\mathrm{KET}_{\text {nano }}$ gel ointment also tended to
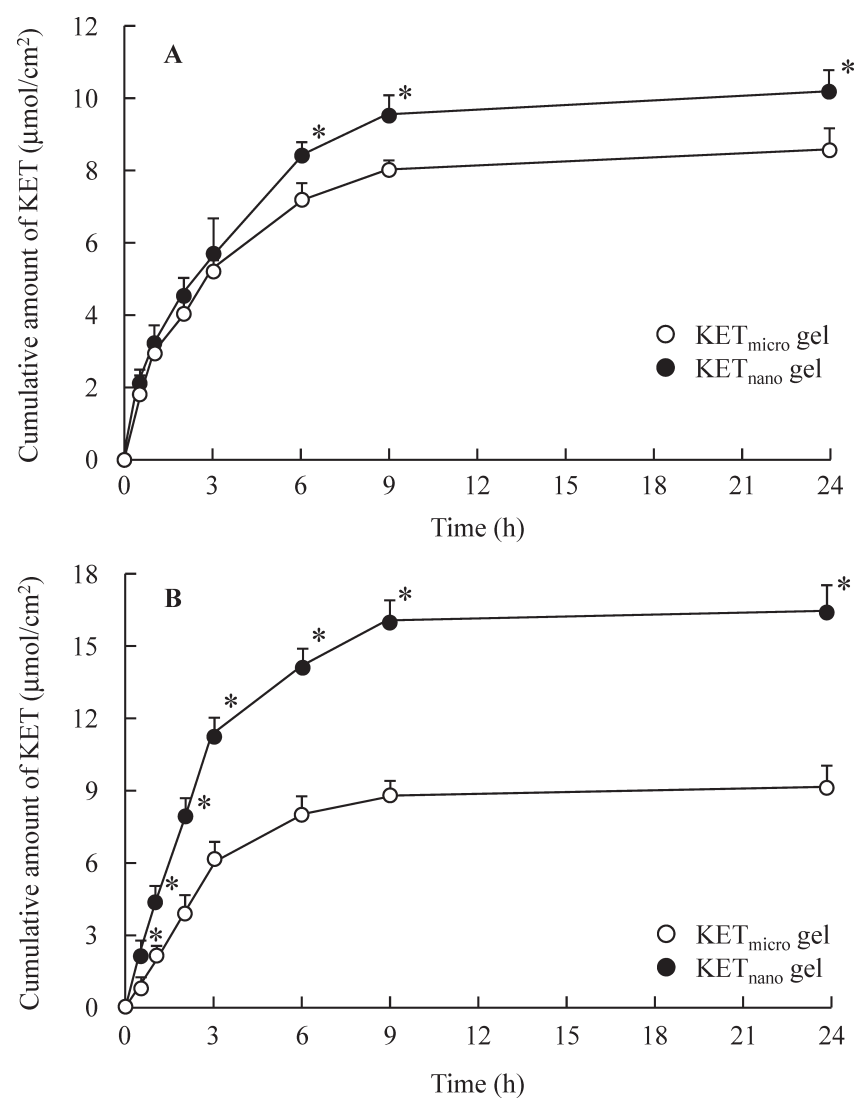

Fig. 2. Release of KET from $\mathrm{KET}_{\text {micro }}$ and $\mathrm{KET}_{\text {nano }}$ Gel Ointments through $25 \mathrm{~nm}$ (A) and $220 \mathrm{~nm}$ (B) Pore Size Membrane

$\mathrm{KET}_{\text {micro }}$ gel (open circles): gel ointment containing KET microparticles. $\mathrm{KET}_{\text {nano }}$ gel (closed circles): gel ointment containing KET nanoparticles. The data represent the mean \pm S.E. of 6 independent experiments. $* p<0.05 v s . \mathrm{KET}_{\text {micro }}$ gel ointment for each category. increase in comparison with the $\mathrm{KET}_{\text {micro }}$ gel ointment (Table 2). In addition, the amounts of KET in the skin tissues of rats receiving the $\mathrm{KET}_{\text {nano }}$ gel ointment were significantly higher than those of rats receiving the $\mathrm{KET}_{\text {micro }}$ gel ointment (Fig. 5). These results show that the formulation of a topical drug

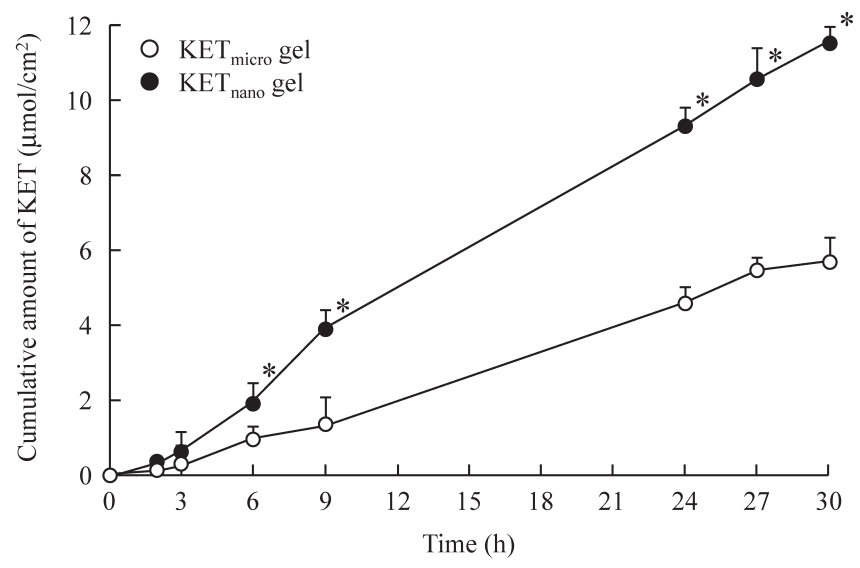

Fig. 3. In Vitro Skin Penetration of KET Released from $\mathrm{KET}_{\text {micro }}$ and $\mathrm{KET}_{\text {nano }}$ Gel Ointments

$\mathrm{KET}_{\text {micro }}$ gel (open circles): gel ointment containing KET microparticles. $\mathrm{KET}_{\text {}}$ gel (closed circles): gel ointment containing KET nanoparticles. The data represent the mean \pm S.E. of 6 rat skins. $* p<0.05 v s$. $\mathrm{KET}_{\text {micro }}$ gel ointment.

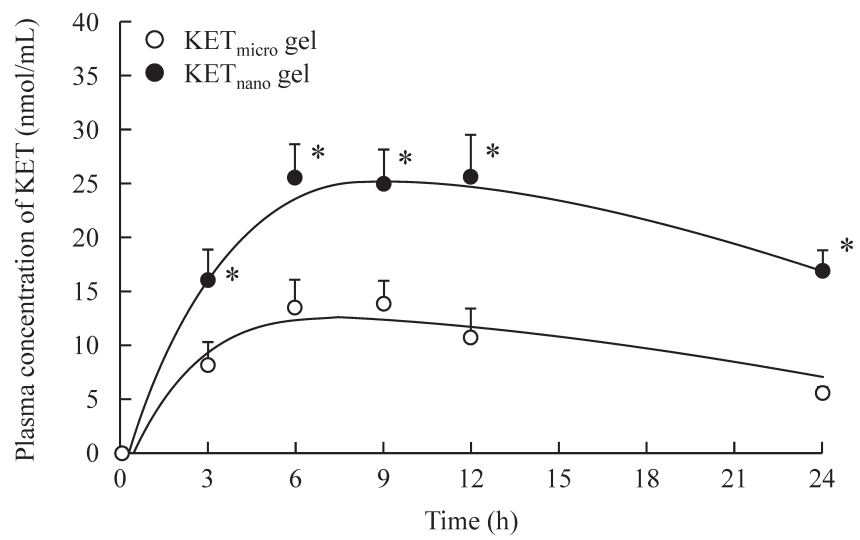

Fig. 4. Changes in Plasma KET Concentration after the Application of $\mathrm{KET}_{\text {micro }}$ and $\mathrm{KET}_{\text {nano }}$ Gel Ointments

$\mathrm{KET}_{\text {micro }}$ gel (open circles): gel ointment containing KET microparticles. $\mathrm{KET}_{\text {nano }}$ gel (closed circles): gel ointment containing KET nanoparticles. Solid lines represent the fitted curves for the application of $\mathrm{KET}_{\text {micro }}$ and $\mathrm{KET}_{\text {nano }}$ gel ointments. The data represent the mean \pm S.E. of 6 rats. ${ }^{*} p<0.05 v s$. $\mathrm{KET}_{\text {micro }}$ gel ointment.

Table 1. Pharmacokinetic Parameters for the in Vitro Skin Penetration of KET Released from $3 \% \mathrm{KET}_{\text {micro }}$ and $\mathrm{KET}_{\text {nano }}$ Gel Ointments

\begin{tabular}{lccccc}
\hline \hline Ointment & $J_{\mathrm{c}}\left(\mathrm{nmol} / \mathrm{cm}^{2} / \mathrm{h}\right)$ & $K_{\mathrm{p}}\left(\times 10^{-3} \mathrm{~cm} / \mathrm{h}\right)$ & $K_{\mathrm{m}}$ & $t_{\mathrm{lag}}(\mathrm{h})$ & $D\left(\times 10^{-3} \mathrm{~cm}^{2} / \mathrm{h}\right)$ \\
\hline $\mathrm{KET}_{\text {micro }}$ gel & $182 \pm 9$ & $5.1 \pm 0.25$ & $0.39 \pm 0.13$ & $0.88 \pm 0.28$ & $1.14 \pm 0.29$ \\
$\mathrm{KET}_{\text {nano }}$ gel & $316 \pm 19^{*}$ & $8.9 \pm 0.55^{*}$ & $0.61 \pm 0.21$ & $0.75 \pm 0.22$ & $1.58 \pm 0.43$ \\
\hline
\end{tabular}

$\mathrm{KET}_{\text {micro }}$ gel: gel ointment containing KET microparticles, $\mathrm{KET}_{\text {nano }}$ gel: gel ointment containing KET nanoparticles. The data represent the mean \pm S.E. of 6 rat skins. $* p<0.05$ vs. $\mathrm{KET}_{\text {micro }}$ gel ointment for each category.

Table 2. Pharmacokinetic Parameters for the in Vivo Percutaneous Absorption of KET Released from $3 \%$ KET $_{\text {micro }}$ and KET ${ }_{\text {nano }}$ Gel Ointments

\begin{tabular}{llcc}
\hline \hline Ointment & $k_{\mathrm{a}}\left(\mathrm{h}^{-1}\right)$ & $t_{\text {lag }}(\mathrm{h})$ & $A U C(\mathrm{nmol} \cdot \mathrm{h} / \mathrm{mL})$ \\
\hline $\mathrm{KET}_{\text {micro }}$ gel & $0.46 \pm 0.16$ & $0.43 \pm 0.10$ & $298 \pm 25$ \\
$\mathrm{KET}_{\text {nano }}$ gel & $1.85 \pm 0.42^{*}$ & $0.27 \pm 0.09$ & $9.24 \pm 1.46$ \\
\hline
\end{tabular}

$\alpha 33.0 \pm 5.6 \mathrm{~h}^{-1}, \beta 0.47 \pm 0.11 \mathrm{~h}^{-1}, A 10.9 \pm 1.87 \mathrm{nmol} / \mathrm{mL}, B \quad 6.14 \pm 0.47 \mathrm{nmol} / \mathrm{mL}$. KET ${ }_{\text {mero }}$ gel: gel ointment containing KET microparticles; KET taining KET nanoparticles. The data represent the mean \pm S.E. of 6 rats. $* p<0.05 v$ s. $\mathrm{KET}_{\text {micro }}$ gel ointment for each category. 
delivery system using KET nanoparticles provides a high level of skin penetration and drug accumulation in skin tissue, and an increase in the percutaneous absorption of KET.

It is important to prove the mechanism of the enhanced

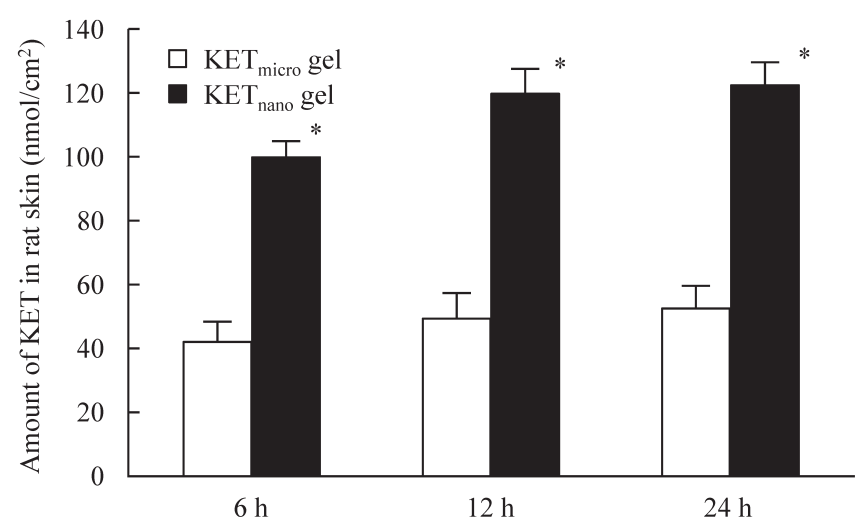

Fig. 5. Amount of KET in Rat Skin Tissue 6-24h after the Application of $\mathrm{KET}_{\text {micro }}$ and $\mathrm{KET}_{\text {nano }}$ Gel Ointments

$\mathrm{KET}_{\text {micro }}$ gel (open columns): gel ointment containing KET microparticles. $\mathrm{KET}_{\text {nano }}$ gel (closed columns): gel ointment containing KET nanoparticles. The data represent the mean \pm S.E. of 6 rats. ${ }^{*} p<0.05 v s$. $\mathrm{KET}_{\text {micro }}$ gel for each category. skin penetration of the topical formulations containing solid nanoparticles. We previously designed gel ointments containing tranilast $\left(\mathrm{TL}_{\text {nano }}\right)$ or indomethacin $\left(\mathrm{IMC}_{\text {nano }}\right)$ nanopariticles (mean particle size: $\mathrm{TL}_{\text {nano }} 79 \pm 152 \mathrm{~nm}, \mathrm{IMC}_{\text {nano }} 186 \pm 101 \mathrm{~nm}$, mean \pm S.D.), and reported their skin penetration parameters. $^{32,33)}$ The skin penetration profile and drug accumulation in skin tissue were similar for the $\mathrm{TL}_{\text {nano }}$ and $\mathrm{IMC}_{\text {nano }}$ gel ointments, and higher than for the micro gel ointments containing $\mathrm{TL}$ and IMC ( $\mathrm{TL}_{\text {micro }}$ and $\mathrm{IMC}_{\text {micro }}$ gel ointments). ${ }^{32,33)}$ These results were the same as the current results for the KET gel ointments. In addition, in the in vitro skin penetration experiments, the penetration rate of the $\mathrm{IMC}_{\text {nano }}$ gel ointment (particle size $186 \mathrm{~nm}$ ) was higher than that of an ointment containing dissolved IMC (commercially available IMC gel ointment, IDOMETHINE $_{\text {KOWA }}$ gel $\left.1 \%\right),{ }^{33)}$ and the skin penetration of the $\mathrm{KET}_{\text {nano }}$ gel ointment (particle size $83 \mathrm{~nm}$ ) is also significantly higher than that $\left(J_{c} 274 \pm 13 \mathrm{nmol} / \mathrm{cm}^{2} / \mathrm{h}, n=6\right)$ of the ointment containing dissolved KET (commercially available KET gel ointment, SECTOR gel ${ }^{\circledR} 3 \%$ ). Taken together, we hypothesize that drug infiltration into the skin tissue is enhanced for particles in the size range of approximately $80-200 \mathrm{~nm}$ in comparison with drugs in the liquid state, and this increase in drug infiltration may cause the high skin penetration and drug
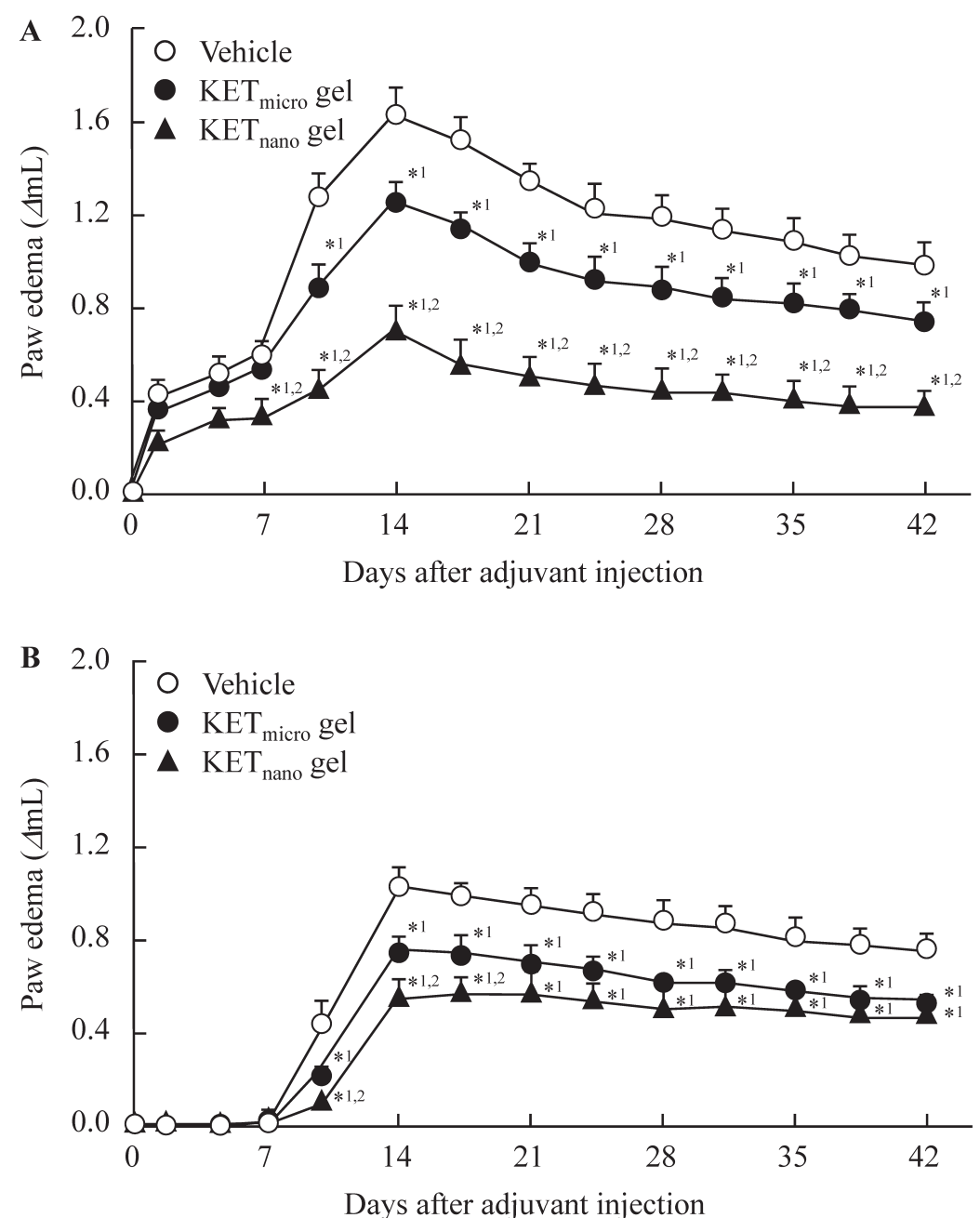

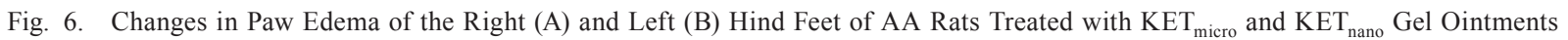

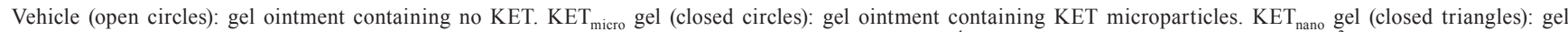
ointment containing KET nanoparticles. The data are presented as mean \pm S.E. of 6 independent rats. ${ }^{* 1} p<0.05 v s$. Vehicle for each category. $* 2 p<0.05 v s$. KET ${ }_{\text {micro }}$ gel ointment for each category. 
accumulation in the skin tissue for the nano gel ointments. In contrast to the results in skin penetration and drug accumulation in skin tissue, the plasma concentration behavior of the $\mathrm{TL}_{\text {nano }}$ gel ointment differed from that of the $\mathrm{IMC}_{\text {nano }}$ gel ointment in in vivo percutaneous absorption experiments. ${ }^{32,33)}$ No difference in $A U C$ was observed between the $\mathrm{IMC}_{\text {micro }}$ and $\mathrm{IMC}_{\text {nano }}$ gel ointments. However, the plasma concentration following the administration of the $\mathrm{TL}_{\text {nano }}$ and $\mathrm{KET}_{\text {nano }}$ gel ointments was higher than that following the administration of the $\mathrm{TL}_{\text {micro }}$ and $\mathrm{KET}_{\text {micro }}$ gel ointments. In addition, the plasma concentration following the administration of the $\mathrm{TL}_{\text {nano }}$ and $\mathrm{KET}_{\text {nano }}$ gel ointments was lower than that following the administration of the ointments containing the dissolved drugs (commercially available ointments) ${ }^{32)}$; and the $A U C$ of the commercially available KET ointment was $801 \pm 51 \mathrm{nmol} \cdot \mathrm{h} /$ $\mathrm{mL}$ (mean \pm S.E., $n=6$ rats). It has been reported that drug solubility can be expected to be enhanced at particle sizes less than $100 \mathrm{~nm}^{44)}$ From these results and reports, it is possible that the solubilities of the drugs in the $\mathrm{TL}_{\text {nano }}$ and $\mathrm{KET}_{\text {nano }}$ gel ointments are higher than in the micro gel ointments in skin tissue, while the IMC solubility in the $\mathrm{IMC}_{\text {nano }}$ gel ointment may not be enhanced since the particle size $(186 \mathrm{~nm})$ is over $100 \mathrm{~nm}$. It is hypothesized that solid drugs that infiltrate into the skin tissue are dissolved, and that the liquid drugs can then shift into the blood. On the other hand, it is important to clarify the precise mechanism of the skin penetration of gel ointments containing drug nanoparticles. Therefore, we are now preparing gel ointments containing particles of various sizes, and investigating their characteristics including skin penetration, drug accumulation in skin tissue and percutaneous absorption.

Anti-inflammatory Effects of KET micro and KET $_{\text {nano }}$ Gel Ointments on Paw Edema in AA Rats In a clinical experiment, a KET gel ointment was used to treat RA. Therefore, we investigated the anti-inflammatory effect of the $\mathrm{KET}_{\text {nano }}$ gel ointment on RA using AA rats as a model. ${ }^{45-48)}$ Paw edema of the right and left hind feet of AA rats to which the $\mathrm{KET}_{\text {micro }}$ and $\mathrm{KET}_{\text {nano }}$ gel ointments were applied was significantly less in comparison with AA rats treated with gel ointment without KET (control gel ointment) in the days following adjuvant injection. The paw edema of the right and left hind feet of AA rats receiving the $\mathrm{KET}_{\text {nano }}$ gel ointment was less than that of AA rats receiving the $\mathrm{KET}_{\text {micro }}$ gel ointment (Fig. 6). In addition, the $A U C_{\text {edema }}$ values of the right hind feet of AA rats treated with the $\mathrm{KET}_{\text {nano }}$ gel ointment were significantly lower than those of AA rats treated with the $\mathrm{KET}_{\text {micro }}$ or control gel ointments (Table 3). These data support the results in which the KET concentrations in the skin tissue and plasma of rats receiving the $\mathrm{KET}_{\text {nano }}$ gel ointment were higher (Table 2, Figs. 4, 5). Moreover, we measured the anti-inflammatory effect following the application of a commercially available KET gel ointment (SECTOR gel $^{\circledR} 3 \%$ ) to compare it with the $\mathrm{KET}_{\text {nano }}$ gel ointment. Although the $A U C_{\text {edema }}$ values in the right feet of AA rats treated with $\mathrm{KET}_{\text {nano }}$ gel ointment were significantly lower than those of $\mathrm{AA}$ rats treated with the commercially available ointment, the $A U C_{\text {edema }}$ values in the left feet of AA rats treated with $\mathrm{KET}_{\text {nano }}$ gel ointment were higher than those of AA rats treated with the commercially available ointment (right hind feet $33.7 \pm 1.5$, left hind feet $19.0 \pm 1.1 \mathrm{~mL} \cdot \mathrm{d}$, the mean \pm S.E., $n=6$ rats). From these data, the achievement of relatively high local KET concentrations in the case of the
Table 3. Preventive Effects of $3 \% \mathrm{KET}_{\text {micro }}$ and $\mathrm{KET}_{\text {nano }}$ Gel Ointments on Paw Edema in AA Rats

\begin{tabular}{lll}
\hline \hline \multirow{2}{*}{ Ointment } & \multicolumn{2}{c}{$A U C_{\text {edema }}(\mathrm{mL} \cdot \mathrm{d})$} \\
\cline { 2 - 3 } & \multicolumn{1}{c}{ Right } & \multicolumn{1}{c}{ Left } \\
\hline Control & $50.8 \pm 2.2$ & $32.9 \pm 1.5$ \\
Vehicle & $50.1 \pm 2.5$ & $32.5 \pm 1.9$ \\
$\mathrm{KET}_{\text {micro }}$ gel & $41.0 \pm 2.2^{* 1,2}$ & $24.6 \pm 1.5^{* 1,2}$ \\
$\mathrm{KET}_{\text {nano }}$ gel & $29.3 \pm 2.1^{* 1,2,3}$ & $21.7 \pm 1.8^{* 1,2}$ \\
\hline
\end{tabular}

Control: untreated AA rat; Vehicle: AA rat treated with gel ointment without $\mathrm{KET}$; $\mathrm{KET}_{\text {micro }}$ gel: AA rat treated with gel ointment containing KET microparticles; $\mathrm{KET}_{\text {nano }}$ gel: AA rat treated with gel ointment containing KET nanoparticles. The data represent the mean \pm S.E. of 6 independent rats. ${ }^{* 1} p<0.05 v$ s. Control for each category. ${ }^{* 2} p<0.05 v s$. Vehicle for each category. ${ }^{* 3} p<0.05 v s$. $\mathrm{KET}_{\text {micro }}$ gel for each category.

$\mathrm{KET}_{\text {nano }}$ gel ointment may result in effective therapy, while the systemic influence of the $\mathrm{KET}_{\text {nano }}$ gel ointment may be lower than that of the commercially available ointment. Further studies are needed in which some mechanistic and/or surrogate biomarkers are carefully monitored.

\section{CONCLUSION}

In this study, we have developed a novel topical drug delivery system that includes KET nanoparticles. KET released from the $\mathrm{KET}_{\text {nano }}$ gel ointment accumulates highly in skin tissue, while the plasma KET concentrations are lower than in the case of the commercially available KET gel ointment. In addition, the anti-inflammatory effect on local inflammation of the $\mathrm{KET}_{\text {nano }}$ gel ointment is significantly greater than those of the $\mathrm{KET}_{\text {micro }}$ and commercially available KET gel ointments. The $\mathrm{KET}_{\text {nano }}$ gel ointment may provide efficient and effective therapy for RA.

Conflict of Interest The authors declare no conflict of interest.

\section{REFERENCES}

1) Paolino D, Ventura CA, Nistico S, Puglisi G, Fresta M. Lecithin microemulsions for the topical administration of ketoprofen: percutaneous adsorption through human skin and in vivo human skin tolerability. Int. J. Pharm., 244, 21-31 (2002).

2) Heyneman CA, Lawless-Liday C, Wall GC. Oral versus topical NSAIDs in rheumatic diseases: a comparison. Drugs, 60, 555-574 (2000).

3) Banga AK. Transdermal and Intradermal Delivery of Therapeutic Agents: Application of Physical Technologies. CRC Press, Taylor \& Francis Group, Boca Raton, FL, p. 309 (2011).

4) Kim BS, Won M, Yang, Lee KM, Kim CS. In vitro permeation studies of nanoemulsions containing ketoprofen as a model drug. Drug Deliv., 15, 465-469 (2008).

5) Valenta C, Almasi-Szabo I. In vitro diffusion studies of ketoprofen transdermal therapeutic systems. Drug Dev. Ind. Pharm., 21, 1799-1805 (1995).

6) Shah PP, Desai PR, Singh M. Effect of oleic acid modified polymeric bilayered nanoparticles on percutaneous delivery of spantide II and ketoprofen. J. Control. Release, 158, 336-345 (2012).

7) Maestrelli F, Gonzalez-Rodriguez ML, Rabasco AM, Mura P. Preparation and characterisation of liposomes encapsulating ketoprofen-cyclodextrin complexes for transdermal drug delivery. Int. J. Pharm., 298, 55-67 (2005).

8) Goosen C, du Plessis J, Müller DG, Janse van Rensburg LF. Cor- 
relation between physicochemical characteristics, pharmacokinetic properties and transdermal absorption of NSAID's. Int. J. Pharm., 163, 203-209 (1998).

9) Beetge E, du Plessis J, Muller DG, Goosen C, van Rensburg FJ. The influence of the physicochemical characteristics and pharmacokinetic properties of selected NSAID's on their transdermal absorption. Int. J. Pharm., 193, 261-264 (2000).

10) Gürol Z, Hekimoğlu S, Demirdamar R, Şumnu M. Percutaneous absorption of ketoprofen. I. In vitro release and percutaneous absorption of ketoprofen from different ointment bases. Pharm. Acta Helv., 71, 205-212 (1996).

11) Shinkai N, Korenaga K, Mizu H, Yamauchi H. Intra-articular penetration of ketoprofen and analgesic effects after topical patch application in rats. J. Control. Release, 131, 107-112 (2008).

12) Shinkai N, Korenaga K, Okumura Y, Mizu H, Yamauchi H. Microdialysis assessment of percutaneous penetration of ketoprofen after transdermal administration to hairless rats and domestic pigs. Eur. J. Pharm. Biopharm., 78, 415-421 (2011).

13) So JW, Park HH, Lee SS, Kim DC, Shin SC, Cho CW. Effect of microneedle on the pharmacokinetics of ketoprofen from its transdermal formulations. Drug Deliv., 16, 52-56 (2009).

14) Panus PC, Campbell J, Kulkarni SB, Herrick RT, Ravis WR, Banga AK. Transdermal iontophoretic delivery of ketoprofen through human cadaver skin and in humans. J. Control. Release, 44, 113-121 (1997).

15) Tashiro Y, Kato Y, Hayakawa E, Ito K. Iontophoretic transdermal delivery of ketoprofen: effect of iontophoresis on drug transfer from skin to cutaneous blood. Biol. Pharm. Bull., 23, 1486-1490 (2000).

16) Sharma DN, Hanesh M, Ali A, Mohamed M. Phonophoresis with diclofenac versus ketoprofen for knee joint injuries. Middle East $J$. Int. Med, 2, 9-12 (1999).

17) Cagnie B, Vinck E, Rimbaut S, Vanderstraeten G. Phonophoresis versus topical application of ketoprofen: comparison between tissue and plasma levels. Phys. Ther., 83, 707-712 (2003).

18) DeLouise LA. Applications of nanotechnology in dermatology. $J$. Invest. Dermatol., 132, 964-975 (2012).

19) Gao X, Cui Y, Levenson RM, Chung LW, Nie S. In vivo cancer targeting and imaging with semiconductor quantum dots. Nat. Biotechnol., 22, 969-976 (2004).

20) Moghimi SM, Hunter AC, Murray JC. Nanomedicine: current status and future prospects. FASEB J., 19, 311-330 (2005).

21) Al-Jamal WT, Al-Jamal KT, Tian B, Cakebread A, Halket JM, Kostarelos K. Tumor targeting of functionalized quantum dotliposome hybrids by intravenous administration. Mol. Pharm., 6, $520-530$ (2009).

22) Boisselier E, Astruc D. Gold nanoparticles in nanomedicine: preparations, imaging, diagnostics, therapies and toxicity. Chem. Soc. Rev., 38, 1759-1782 (2009).

23) Debbage P. Targeted drugs and nanomedicine: present and future. Curr. Pharm. Des., 15, 153-172 (2009).

24) Huang HC, Barua S, Sharma G, Dey SK, Rege K. Inorganic nanoparticles for cancer imaging and therapy. J. Control. Release, 155, 344-357 (2011).

25) Huang X, Peng X, Wang Y, Wang Y, Shin DM, El-Sayed MA, Nie S. A reexamination of active and passive tumor targeting by using rod-shaped gold nanocrystals and covalently conjugated peptide ligands. ACS Nano, 4, 5887-5896 (2010).

26) Ilbasmiş-Tamer S, Yilmaz S, Banoğlu E, Değim IT. Carbon nanotubes to deliver drug molecules. J. Biomed. Nanotechnol., 6, 20-27 (2010).

27) Chouly C, Pouliquen D, Lucet I, Jeune JJ, Jallet P. Development of superparamagnetic nanoparticles for MRI: effect of particle size, charge and surface nature on biodistribution. J. Microencapsul., 13, 245-255 (1996).

28) Begley DJ. Delivery of therapeutic agents to the central nervous system: the problems and the possibilities. Pharmacol. Ther., 104,
29-45 (2004).

29) Bareford LM, Swaan PW. Endocytic mechanisms for targeted drug delivery. Adv. Drug Deliv. Rev., 59, 748-758 (2007).

30) Dobrovolskaia MA, Aggarwal P, Hall JB, McNeil SE. Preclinical studies to understand nanoparticle interaction with the immune system and its potential effects on nanoparticle biodistribution. Mol. Pharm., 5, 487-495 (2008).

31) Toy R, Peiris PM, Ghaghada KB, Karathanasis E. Shaping cancer nanomedicine: the effect of particle shape on the in vivo journey of nanoparticles. Nanomedicine, 9, 121-134 (2014).

32) Nagai N, Ito Y. Therapeutic effects of gel ointments containing tranilast nanoparticles on paw edema in adjuvant-induced arthritis rats. Biol. Pharm. Bull., 37, 96-104 (2014).

33) Nagai N, Yoshioka $\mathrm{C}$, Ito Y. Topical therapies for rheumatoid arthritis by gel ointments containing indomethacin nanoparticles in adjuvant-induced arthritis rat. J. Oleo Sci., 64, 337-346 (2015).

34) Cohen S, Yoshioka T, Lucarelli M, Hwang LH, Langer R. Controlled delivery systems for proteins based on poly(lactic/glycolic acid) microspheres. Pharm. Res., 8, 713-720 (1991).

35) Tomoda K, Terashima H, Suzuki K, Inagi T, Terada H, Makino K. Enhanced transdermal delivery of indomethacin-loaded PLGA nanoparticles by iontophoresis. Colloids Surf. B Biointerfaces, 88, 706-710 (2011).

36) Tomoda K, Terashima H, Suzuki K, Inagi T, Terada H, Makino K. Enhanced transdermal delivery of indomethacin using combination of PLGA nanoparticles and iontophoresis in vivo. Colloids Surf. $B$ Biointerfaces, 92, 50-54 (2012).

37) Tomoda K, Watanabe A, Suzuki K, Inagi T, Terada H, Makino K. Enhanced transdermal permeability of estradiol using combination of PLGA nanoparticles system and iontophoresis. Colloids Surf. B Biointerfaces, 97, 84-89 (2012).

38) Nagai N, Yoshioka C, Mano Y, Tnabe W, Ito Y, Okamoto N, Shimomura Y. A nanoparticle formulation of disulfiram prolongs corneal residence time of the drug and reduces intraocular pressure. Exp. Eye Res., 132, 115-123 (2015).

39) Nagai N, Ito Y. Effect of solid nanoparticle of indomethacin on therapy for rheumatoid arthritis in adjuvant-induced arthritis rat. Biol. Pharm. Bull., 37, 1109-1118 (2014).

40) Nagai N, Ito Y, Okamoto N, Shimomura Y. A nanoparticle formulation reduces the corneal toxicity of indomethacin eye drops and enhances its corneal permeability. Toxicology, 319, 53-62 (2014).

41) Nagai N, Ono H, Hashino M, Ito Y, Okamoto N, Shimomura Y. Improved corneal toxicity and permeability of tranilast by the preparation of ophthalmic formulations containing its nanoparticles. J. Oleo Sci., 63, 177-186 (2014).

42) Yamaoka K, Tanigawara Y, Nakagawa T, Uno T. A pharmacokinetic analysis program (multi) for microcomputer. J. Pharmacobiodyn., $\mathbf{4}$ 879-885 (1981).

43) Ito Y, Ogiso T, Iwaki M, Tanino T, Terao M. Percutaneous absorption of acemetacin from a membrane controlled transdermal system and prediction of the disposition of the drug in rats. Biol. Pharm. Bull., 16, 583-588 (1993).

44) Moribe K, Higashi K. Nanocrystal formulation of poorly watersoluble drug. Drug Deliv. Syst., 30, 92-99 (2015).

45) Billingham ME. Models of arthritis and the search for anti-arthritic drugs. Pharmacol. Ther., 21, 389-428 (1983).

46) Sakuma S, Nishigaki F, Magari K, Ogawa T, Miyata S, Ohkubo Y, Goto T. FK506 is superior to methotrexate in therapeutic effects on advanced stage of rat adjuvant-induced arthritis. Inflamm. Res., 50, 509-514 (2001).

47) Kato S, Takeuchi K. Alteration of gastric ulcerogenic and healing responses in rats with adjuvant-induced arthritis. Jpn. J. Pharmacol., 89, 1-6 (2002).

48) Kato S. Changes in ulcerogenic response to non-steroidal antiinflammatory drugs (NSAIDs) in adjuvant arthritic rats. Yakugaku Zasshi, 121, 743-751 (2001). 